\title{
ERGONOMIC WORKPLACE DESIGN FOR WORKERS WITH DISABILITIES
}

\section{VujicA Herzog, N., BuChMEISTER, B., \& HARIH, G.}

Abstract: Work is one of the basic factors of human life. It is well known that appropriate workplace design can contribute to healthy and satisfied worker and this fact is even more important when we talk about workers with disabilities. In the field of ergonomics workplace design there is rarely any expert knowledge regarding workers with disabilities. Those workers are also more sensitive for stress at work and possible injuries that are usually connected with non-adequate workplace design. On the other hand, companies face the problem of identifying suitable workplaces for workers with disabilities, and supplying the needed requirements to integrate them with other healthy workers. The purpose of our research was to present an approach of ergonomically designed workplace for workers with disabilities. Manual and computer aided OWAS analyses were performed to assess present indicator light assembly workplace in a large sized production company.

Key words: ergonomics, occupational ergonomics, workers with disabilities, ergonomics workplace design
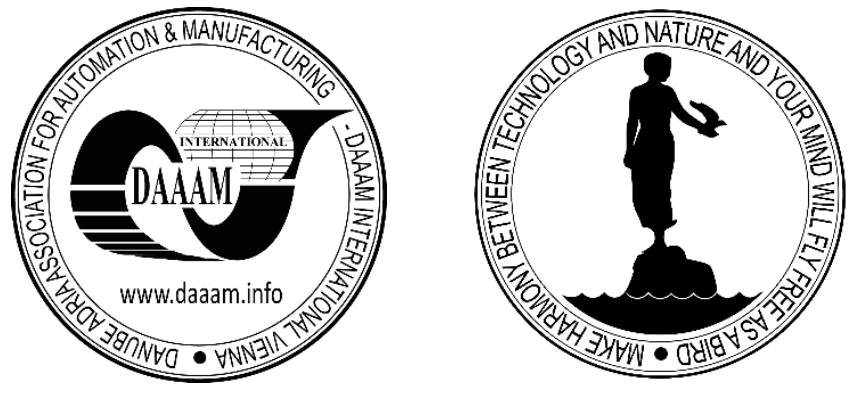

Authors' data: Assoc. Prof. Dr. Sc. Vujica Herzog, N[atasa], Full. Prof. Dr. Sc. Buchmeister, B[orut]; Asist. Prof. Dr. Sc. Harih, G[regor];University of Maribor, Faculty of Mechanical Engineering, Smetanova 17, 2000 Maribor, Slovenia, natasa.vujica@um.si, borut.buchmeister@um.si,gregor.harih@um.si

This Publication has to be referred as: Vujica Herzog, N[atasa]; Buchmeister, B[orut] \& Harih, G[regor] (2019). Ergonomic Workplace Design for Workers with Disabilities, Chapter 12 in DAAAM International Scientific Book 2019, pp.159-174, B. Katalinic (Ed.), Published by DAAAM International, ISBN 978-3-902734-24-2, ISSN 1726-9687, Vienna, Austria

DOI: $10.2507 /$ daaam.scibook.2019.12 
Vujica Herzog, N.; Buchmeister, B. \& Harih, G.: Ergonomic Workplace Design for...

\section{Introduction}

People with disabilities represent a large population around the globe. The World Health Organization estimates that about 15 to $19 \%$ of the adult population worldwide (about one billion people) have disabilities (World report on disability, 2011). Since many disabilities is age related the number and proportion are expected to increase with the aging the population (Schur et al., 2016). People with disabilities have generally poorer health, lower education achievements, fewer economic opportunities and higher rates of poverty than people without disabilities.

Generally all jobs can be performed by someone with a disability, and given the right environment, but several studies show, that persons with disabilities experience significantly lower employment rates and much higher unemployment rates than persons without disabilities (Houtenville et al., 2009; Contreras et al., 2006; Mete, 2008; Mitra, 2006; Mitra, 2008). Unemployed people with disabilities usually face great barriers in becoming employed (Jones, 2006; Jones, 2016; Kruse \& Schur, 2003; Yelln \& Trupin 2003). People with disabilities are also more vulnerable and mostly need additional adjustments to ensure a healthy and safe workplace.

Many employers still believe that workers with disabilities are inferior; therefore, mixed interactions inside the company are still avoided (Lengnick-Hall et al., 2008). Most employers put the workers with disabilities into segregated work environments, where they work together and are usually supervised by workers without disabilities (Kregel \& Dean, 2002). This model assumes that the workers with disabilities are less productive and, therefore, it usually pays a lower wage. These workers are isolated from other workers, and sometimes depend on additional government funds, which makes advancement from the sheltered work environment impossible, which increases the work dissatisfaction between workers with disabilities. As a result, productivity is lowered and there is no community integration (Murphy \& Rogan, 1995).

On the other hand a model Supported Integrated Employment stimulate integration. Upon this model workers with disabilities are assisted during the job search, training and assistance during employment with individual support and needed requirements, which usually results in competitive wages and higher worker satisfaction (Parent-Johnson \& Owens, 2017). In recent years, customized employment has gained traction (Riesen et al., 2015). The employment relationship is customized for each individual, based on the needs, strengths, aspiration, skills and interests of the person with the disability. Workers with disabilities receive support, and are placed in competitive workplaces, which fit their individual needs. Previous research has shown such integrated employment model shows positive employment outcomes for workers with disabilities (Parent-Johnson \& Owens, 2017).

Companies are also concerned with possible injuries at work and absenteeism that is connected with high costs (Abrahamsson, 2000; Genowska et al., 2017; Fritzsche et al., 2014; Yang et al., 2018). Absence from work due to illness is a complex phenomenon, which in a high percentage of cases is determined by the type of work and working conditions (Genowska et al., 2017). Psychosocial environment of work plays one of the most important roles in the overall structure of the reasons for absence from work. 
Level of stress, style of management, quantitative and qualitative requirements of an employer and time pressure have an impact on the well-being and his or her attitude towards professional duties. Rehabilitation in case of injuries and absence from work for any reasons generate high socioeconomic costs. Direct costs are associated with medical care and indirect costs are expressed as loss of productivity.

Employers are, therefore, faced with the complex task of proposing suitable adjustments for workers with disabilities to enable them the best working environment and to increase their satisfaction. By ergonomic workplace design it is possible to adapt work to a human's physical and mental characteristics and to reduce or prevent additional adverse effects on health.

For the purpose of our research, a case study of ergonomic workplace design for workers with disabilities will be presented in large sized Slovenian company from the automotive industry.

\section{Research background}

A case of ergonomic workplace design for workers with disabilities was performed as a part of a project for the "Public Scholarship, Development, Disability and Maintenance Fund of the Republic of Slovenia". The main topic of this project was development of a decision support system for aiding in the process of identifying and categorizing disabilities of workers, and assigning the most suitable workplace with needed requirements in an integrated work environment to ensure high safety, productivity and satisfaction. With decision support system, a step toward prevention of injuries at work was made and tested in a large sized manufacturing company.

Within research we faced also with ergonomics workplace design for workers with disabilities that is the topic of presented paper. In large sized company from automotive industry where the project was performed the majority of workforce works in assembly department. Since most of the worker's activities are related to movements of the upper extremities we used well known ergonomic method OWAS (Karhu et al., 1977; Karhu et al., 1981; Andrejiova 2012; Spyropoulus et al., 2013; Fomin 2015; Vujica Herzog \& Buchmeister, 2014 and 2015) for workers movements assessment.

New workplace design is usually connected with additional costs therefore economic view should be consider, too. There is a lack of comprehensive evaluations of change projects initiated to improve working environments (Abrahamsson, (2000). Upon Abrahamsson the concept of 'change' can have two different meanings. First, it can mean a consciously introduced change at the workplace, for example to build a new workplace, to buy a new piece of equipment or machine or to reduce the numbers in the work team. Secondly, 'change' can mean a consequential change. Some of the consequential changes are due to the new workplace and we can also call them effects, while other consequential changes are effects of the other development projects within the company. Four different categories of effects that should be considered are summarized in Fig. 1. 
Vujica Herzog, N.; Buchmeister, B. \& Harih, G.: Ergonomic Workplace Design for...

\begin{tabular}{c|c|c|}
\multicolumn{1}{c|}{} & $\begin{array}{c}\text { Direct relation } \\
\text { to the new } \\
\text { workplace }\end{array}$ & $\begin{array}{c}\text { Uncertain } \\
\text { relation to the } \\
\text { new workplace }\end{array}$ \\
\cline { 2 - 3 } $\begin{array}{c}\text { Possible to } \\
\text { value in } \\
\text { monetary } \\
\text { terms } \\
\text { Not possible to } \\
\text { value in } \\
\text { monetary } \\
\text { terms }\end{array}$ & 1 & 3 \\
\cline { 2 - 3 } & 2 & 4 \\
& & \\
\end{tabular}

Fig. 1. Four different categories of economic effects

Unemployment is a big problem for all people and even bigger for people with disabilities. Before laying the legislative groundwork, employers would rarely employ people with disabilities at important workplaces in the company. Unemployed people with disabilities usually face great barriers in becoming employed. In Slovenia The National Government developed a quota system for employing workers with disabilities, where every company with more than 20 workers must employ at least $6 \%$ of workers with disabilities, in accordance to the total number of workers. If the quota system is not adhered to by the company, it is forced to pay a contribution to the Fund for promotion of employment of workers with disabilities in the form of $70 \%$ of the minimal wage for each worker with disability. National statistics show that the number of people with disabilities is rising year after year, and, despite incentives for businesses to employ workers with disabilities, some companies still do not achieve full quotas, while, on the other hand, the labor market remains inaccessible for many workers with disabilities.

From about 3,500 employed workers in our selected company 210 workers would present quota (6\% of all workers). Actually, in the time of our research there were 176 workers with disabilities and all of them were considered for testing our developed decision support system. These workers were working in a segregated working environment, separated from the healthy workers. They were working on less demanding tasks such as insertion and quality control. With our developed decision support system and ergonomically based approach for designing workplaces for workers with disabilities, we try to overcome barriers and integrate these workers with other healthy workers in manufacturing.

During our research we faced some problems. The biggest problem was that none of the well-known ergonomics methods such as RULA, OWAS and others, does not include assessment measures for workers with disabilities. The same situation is with the software packages that use digital human models for workers movement simulation and analysis. This presents a great defectiveness that should be addressed in the future. We decided to use ergonomics methods for workplaces assessment nevertheless but with demand that all designed workplaces for workers with disabilities will be assessed as excellent it means withought any possibility for additional injuries for worker. 


\section{Methodology}

Ergonomic workplace design for workers with disabilities has been shown on selected indicator light assembly workplace. To research presented problem the following steps were taken:

- Workplace analysis and evaluation; analysis of the existent workstation dimensions with respect to working postures and workers' perceptions; we observed the healthy worker and assess her movements to assess the suitability of presented workplace first. The observation was conducted over two days, 7,5 hours per day.

- The extended OWAS method was used at indicator light assembly workplace to evaluate the strains caused by different operators' postures.

- The examined workplace was designed and analysed using the Jack software package created by Technomatics.

- Comparison between manually-performed OWAS analysis and software OWAS analysis was made to confirm the reliability of the performed research,

- Based on the results of OWAS analysis certain propositions were advanced for improving working conditions and preventing possible health problems in the future.

- Finally all gathered information's were used to estimate the suitability of workplace for worker with disabilities that was selected for this workplace using developed decision support system.

\section{Manually and computer aided OWAS analysis}

The OWAS method (Ovaco Working Analysing System) is a method of posture monitoring (Karhu et al., 1981; Vujica Herzog et al., 2014). This method originated from Finland's steel industry where body the positions of workers were analysed using an elaboration observation method called OWAS. The method was initially successful and was therefore further developed and modified. It is considered to be a practical method for identifying and evaluating working postures. The OWAS procedure consists of two parts: an observational technique for classifying body postures, and a set of criteria for the redesigning of working methods and workplaces. Body postures are classified into 28 positions including the positions of the back (four positions), upper limbs (four), hands (three), lower limbs (nine), head and neck (five), as well as the load or force handled (three).

Each of these positions has pre-defined high risk and low risk postures that are coded by the observer. After calculating the amount of time the worker maintains these postures, the final step is to assign a four-level action code for task improvement. These four action codes are defined as follows: changes are not needed, changes needed in near future, changes needed immediately, need intensive observation.

Beside manually performed OWAS method we can assess suitability of working postures also with computer aided analysis such as e.g. Jack software created by Siemens PLM. Jack is a complete system for generating 3D environments and interacting with them within a powerful graphical environment. It is based on a detailed link segment model with biologically accurate motion prediction and joint kinematics. 
Vujica Herzog, N.; Buchmeister, B. \& Harih, G.: Ergonomic Workplace Design for...

When using Jack we can design real-time environment with interactive viewing, multiple windows, lights and cameras, textures, and mirrors.

The most important and useful part of Jack software is the possibility of performing different analyses. The Jack analysis toolkit is a set of Ergonomic analysis tools that help us to design better work areas and evaluate physical tasks.

By using different analyses Jack enables us to design a workplace that minimises the risk of low back injuries, determines whether workers have enough strength to perform their prescribed job, design and evaluate lifting jobs, determine the metabolic energy requirements of a job and compare alternative job designs based on their relative risks of exposing workers to fatigue. In addition Jack help us when assessing working postures for their potentials to expose workers to injury, identify manual tasks that expose workers to increased risk of upper limb disorders, evaluate manual handling tasks and predict whether a worker can be expected to perform a job under predefined cyclical-time requirements.

For the detailed analysis of worker postures on the indicator light assembly workplace, we did manually OWAS analysis and used Jack 8.4 software package for OWAS analysis by simulating working postures and performing several analyses.

Each of performed methods have some benefits and some obstacles. Manually performed OWAS is a time-sampling method that requires the time sampling of tasks in intervals that can be planned or randomly selected it is time consuming. On the other hand, for computer aided analysis video tape of working procedure is enough to create virtual workplace, make simulation of all workers movement and perform analysis. We can also observe video many times and thus create environment that is almost identical to real environment including time spent for particular operation.

\section{Case study}

In the presented research, we collaborated with a large sized company from the automotive industry, as presented before. The company specializes in manufacturing and assembly of car body lightning for various brands and models of cars. In our research, we have focused on the workplaces inside manufacturing, and especially the assembly department of the company, which presents the majority of the workforce in the company. Most of the worker's activities are therefore related to movements of the upper extremities.

The existing workplace was assembled using standard company contractor elements with standardized sizing and placement, and without considering workers with disabilities. The workplace required a standing posture with additional twisting and bending of neck, spine and hands while reaching the assembly components. Therefore, the workplace was not suitable for a worker with disabilities in the neck, spine and hand area (Fig. 2). On Fig. 3 the indicator light is presented as real view and computer aided view. 


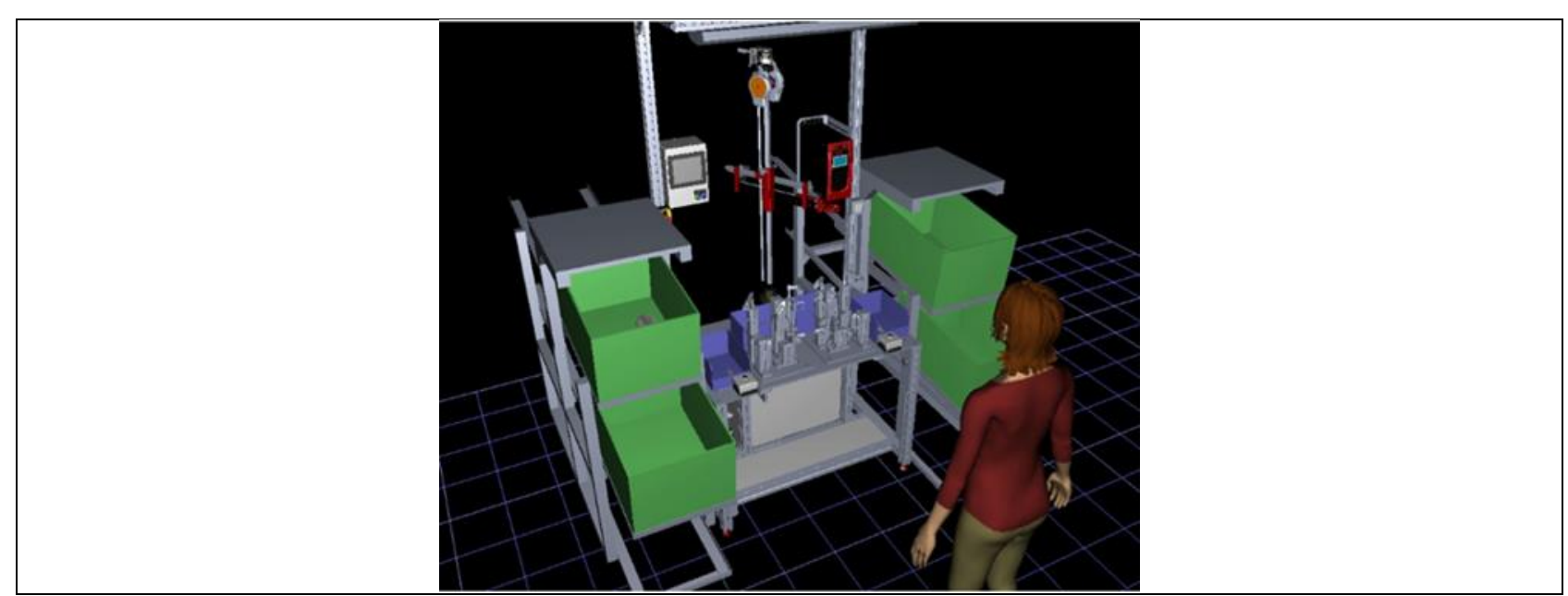

Fig. 2. Indicator light assembly workplace before the adjustments

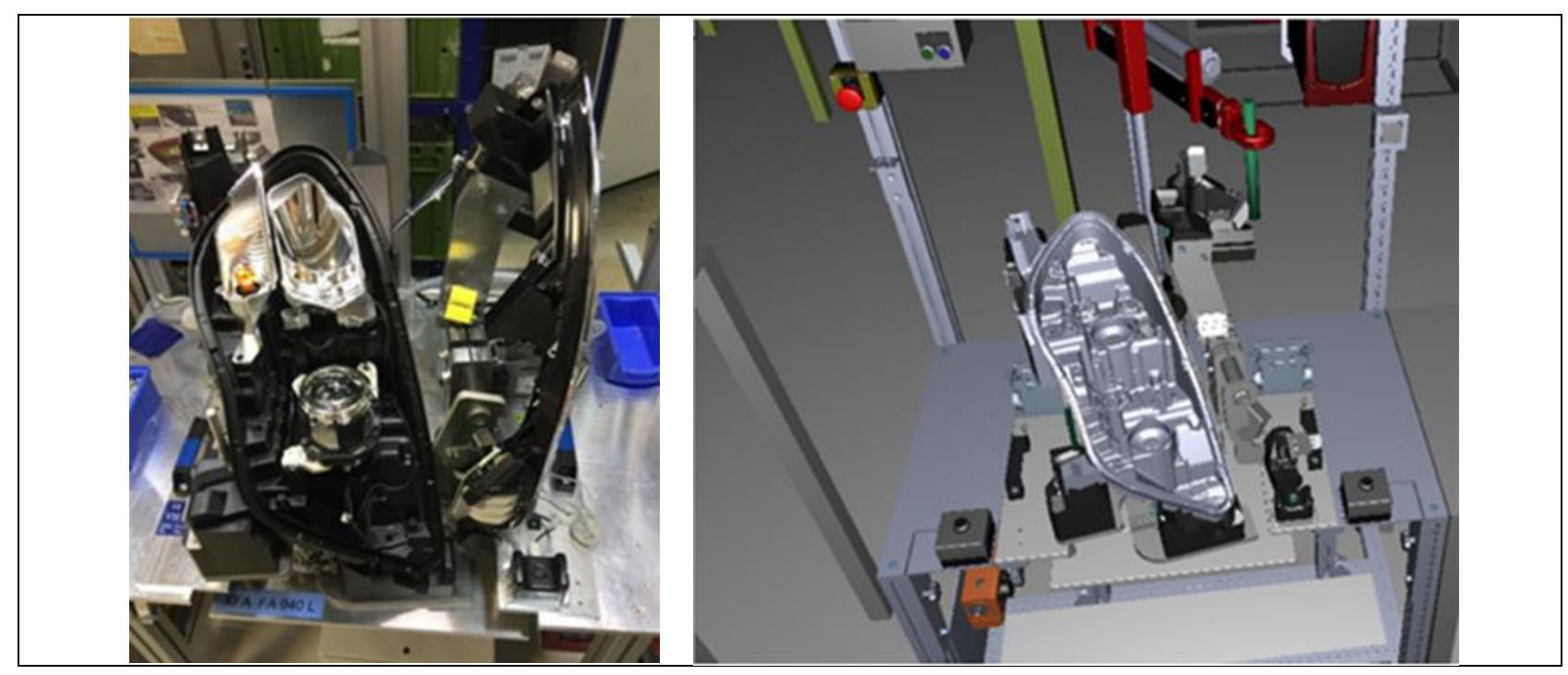

Fig. 3. The indicator light - real view and computer aided view

\section{Workplace analyses and results}

First manually performed OWAS analysis was made. We observed and assessed postures of spine, upper limb, both hands (dominated $-\mathrm{d}$ and no dominated $-\mathrm{n}$ ) and head. Since there is no any special legs movement, we did not observe that body part.

\begin{tabular}{|c|c|c|c|c|c|c|c|c|c|c|c|c|c|c|c|c|c|c|}
\hline \multirow{3}{*}{$\begin{array}{l}\text { Body } \\
\text { Parts }\end{array}$} & \multicolumn{3}{|c|}{\begin{tabular}{|c|}
$\begin{array}{c}\text { Thoraxlumb. } \\
\text { spine }\end{array}$ \\
\end{tabular}} & \multicolumn{4}{|c|}{ Upper limb } & \multicolumn{3}{|c|}{ Hands - d } & \multicolumn{3}{|c|}{ Hands - $\mathrm{n}$} & \multicolumn{5}{|c|}{ Head } \\
\hline & 1.1 & 1.2 & 1.3 & 2.1 & 2.2 & 2.3 & 2.4 & 3.1 & 3.2 & 3.3 & 3.1 & 3.2 & 3.3 & 5.1 & 5.2 & 5.3 & 5.4 & 5.5 \\
\hline & ? & 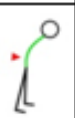 & . & \$ & . 尔. & $\times 9$ & 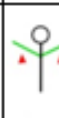 & $\Delta$ & $\Lambda$ & $\angle$ & $\Delta$ & $\Lambda$ & $\angle$ & 9 & 1. & 1. & 9 & b. \\
\hline \begin{tabular}{|l|} 
Nr. of \\
measur.
\end{tabular} & 62 & 58 & 15 & 0 & 91 & 44 & 0 & 108 & 0 & 0 & 116 & 19 & 0 & 41 & 49 & 0 & 15 & 0 \\
\hline$p_{i}[\%]$ & 45,9 & 42,9 & 11,1 & 0 & 67,4 & 32,6 & 0 & 80 & 0 & 0 & 85,7 & 14,3 & 0 & 30,4 & 36,3 & 0 & 11,1 & 0 \\
\hline$t_{p i}[\mathrm{~min}$ & 206,5 & 193 & 49,9 & 0 & 303 & 147 & 0 & 360 & 0 & 0 & 386 & 64,3 & 0 & 136,7 & 163 & 0 & 50 & 0 \\
\hline Measure & 口 & $\bullet$ & 口 & 口 & $\bullet$ & $\bullet$ & 口 & $\star$ & $\square$ & $\square$ & $\star$ & 口 & $\square$ & 口 & $\bullet$ & 口 & $\bullet$ & 口 \\
\hline
\end{tabular}

Tab. 1. OWAS - calculated results with recommended measures 
Vujica Herzog, N.; Buchmeister, B. \& Harih, G.: Ergonomic Workplace Design for...

Results of OWAS observation method are presented in Tab. 1. We calculated percentage of each position (Equation 1) and the time of duration (Equation 2) where $\sum \mathrm{F}_{\mathrm{p}}$ stands for the sum of each body position, and $\left(\sum \mathrm{F}_{\mathrm{s}}\right)$ is the sum of all body positions within each group of working positions.

$$
\begin{aligned}
& p=\frac{\sum F_{p} \cdot 100}{\sum \mathrm{F}_{s}}\lceil \%\rceil \\
& t_{p}=\frac{450 \cdot p}{100}\lceil\mathrm{~min}\rceil
\end{aligned}
$$

The obtained results are compared with the recommended measurement values (Tab. 2) and the results are presented with signs in Tab. 1.

After manually performed OWAS analysis we continue with computer aided

\begin{tabular}{|c|c|c|c|c|c|c|c|c|c|c|c|c|c|c|c|c|}
\hline \multirow{3}{*}{$\begin{array}{c}\text { Body } \\
\text { Parts } \\
\text { OWAS } \\
\%\end{array}$} & \multicolumn{4}{|c|}{$\begin{array}{c}\text { Thoraxlumbal } \\
\text { spine }\end{array}$} & \multicolumn{4}{|c|}{ Upper limb } & \multicolumn{3}{|c|}{ Hands } & \multicolumn{5}{|c|}{ Head } \\
\hline & 1.1 & 1.2 & 1.3 & 1.4 & 2.1 & 2.2 & 2.3 & 2.4 & 3.1 & 3.2 & 3.3 & 5.1 & 5.2 & 5.3 & 5.4 & 5.5 \\
\hline & \{ & 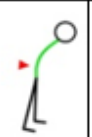 & \{ & {$[0$} & 争 & 우․ & $x$ & .9. & $\Delta$ & $\Lambda$ & $\angle$ & 9 & $1 \%$ & . & 9 & b. \\
\hline 10 & $\square$ & $\square$ & $\square$ & $\bullet$ & $\square$ & $\square$ & $\square$ & $\square$ & $\square$ & 口 & $\square$ & $\square$ & $\square$ & $\square$ & 口 & $\square$ \\
\hline 20 & $\square$ & 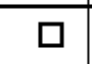 & प & $\bullet$ & $\square$ & 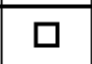 & $\square$ & प & $\square$ & प & प & $\square$ & $\bar{Q}$ & $\square$ & $\bullet$ & 口 \\
\hline 30 & $\square$ & $\square$ & $\bullet$ & $\bullet$ & $\square$ & $\square$ & $\square$ & $\bullet$ & $\square$ & 口 & $\square$ & $\square$ & $\bullet$ & $\bullet$ & $\bullet$ & $\square$ \\
\hline 40 & $\square$ & $\bullet$ & $\bullet$ & $\boldsymbol{\Delta}$ & $\bar{\square}$ & $\bullet$ & $\bullet$ & $\bullet$ & $\square$ & $\bar{\square}$ & $\square$ & $\square$ & $\bullet$ & $\bullet$ & $\boldsymbol{\Delta}$ & $\bullet$ \\
\hline 50 & $\square$ & $\bullet$ & $\bullet$ & $\boldsymbol{\Delta}$ & $\square$ & $\bullet$ & $\bullet$ & $\bullet$ & $\square$ & $\square$ & 口 & $\square$ & $\bullet$ & $\bullet$ & $\boldsymbol{\Delta}$ & $\bar{\theta}$ \\
\hline 60 & $\square$ & $\bullet$ & $\bar{\Delta}$ & $\boldsymbol{\Delta}$ & $\square$ & $\bullet$ & $\bullet$ & $\bullet$ & $\square$ & $\square$ & 口 & $\square$ & $\Delta$ & $\bar{\Delta}$ & $\bar{\Delta}$ & $\bullet$ \\
\hline 70 & $\square$ & $\bullet$ & $\bar{\Delta}$ & $\boldsymbol{\Delta}$ & $\square$ & $\bullet$ & $\bullet$ & $\boldsymbol{\Delta}$ & 口 & 口 & $\square$ & $\square$ & $\boldsymbol{\Delta}$ & $\bar{\Delta}$ & $\boldsymbol{\Delta}$ & $\bullet$ \\
\hline 80 & $\square$ & $\boldsymbol{\Delta}$ & $\boldsymbol{\Delta}$ & $\bar{\Delta}$ & $\square$ & $\overline{\boldsymbol{\Delta}}$ & $\bar{\Delta}$ & $\boldsymbol{\Delta}$ & $\star$ & $\star$ & $\star$ & 口 & $\bar{\Delta}$ & $\boldsymbol{\Delta}$ & $\bar{\Delta}$ & $\bar{\Delta}$ \\
\hline 90 & $\square$ & $\bar{\Delta}$ & $\bar{\Delta}$ & $\boldsymbol{\Delta}$ & $\square$ & $\overline{\boldsymbol{\Delta}}$ & $\bar{\Delta}$ & $\boldsymbol{\Delta}$ & $\star$ & $\star$ & $\star$ & $\square$ & $\bar{\Delta}$ & $\boldsymbol{\Delta}$ & $\bar{\Delta}$ & $\overline{\boldsymbol{\Lambda}}$ \\
\hline 100 & $\square$ & $\bar{\Delta}$ & $\bar{\Delta}$ & $\boldsymbol{\Delta}$ & $\square$ & $\boldsymbol{\Delta}$ & $\overline{\boldsymbol{\Delta}}$ & $\boldsymbol{\Delta}$ & $\star$ & $\star$ & $\star$ & $\square$ & $\bar{\Delta}$ & $\boldsymbol{\Delta}$ & $\bar{\Delta}$ & $\overline{\boldsymbol{\Lambda}}$ \\
\hline
\end{tabular}
OWAS using Jack software package by Technomatics.

Legend for Table 2: $\square$ - changes are not needed $\Delta$ - changes needed immediately - - changes needed in near future $\star$ - needed intensive observation

Tab. 2. OWAS - review table of recommended measures

For the computer aided OWAS analysis (Fig. 4), we did the human movements simulation first. This is the hardest part of analysis because the quality of workers movements depends on the quality of simulation. After successful simulation of workers movements, the performance of different analysis is very easy. The tool evaluates postures based on the position of the back, arms and legs: 
- Back positions are divided into four alternatives based on the degree of bending and twisting,

- Arm positions are divided into three alternatives based on their relation to shoulder level,

- Leg positions are divided into seven alternatives based on whether the human is sitting, standing, kneeling or walking, and whether the legs are bent or straight

We can also attach a load to the Jack human figure or specify the weight of the load in the tools input dialog box. Strength requirements are divided into three categories based on weight load.

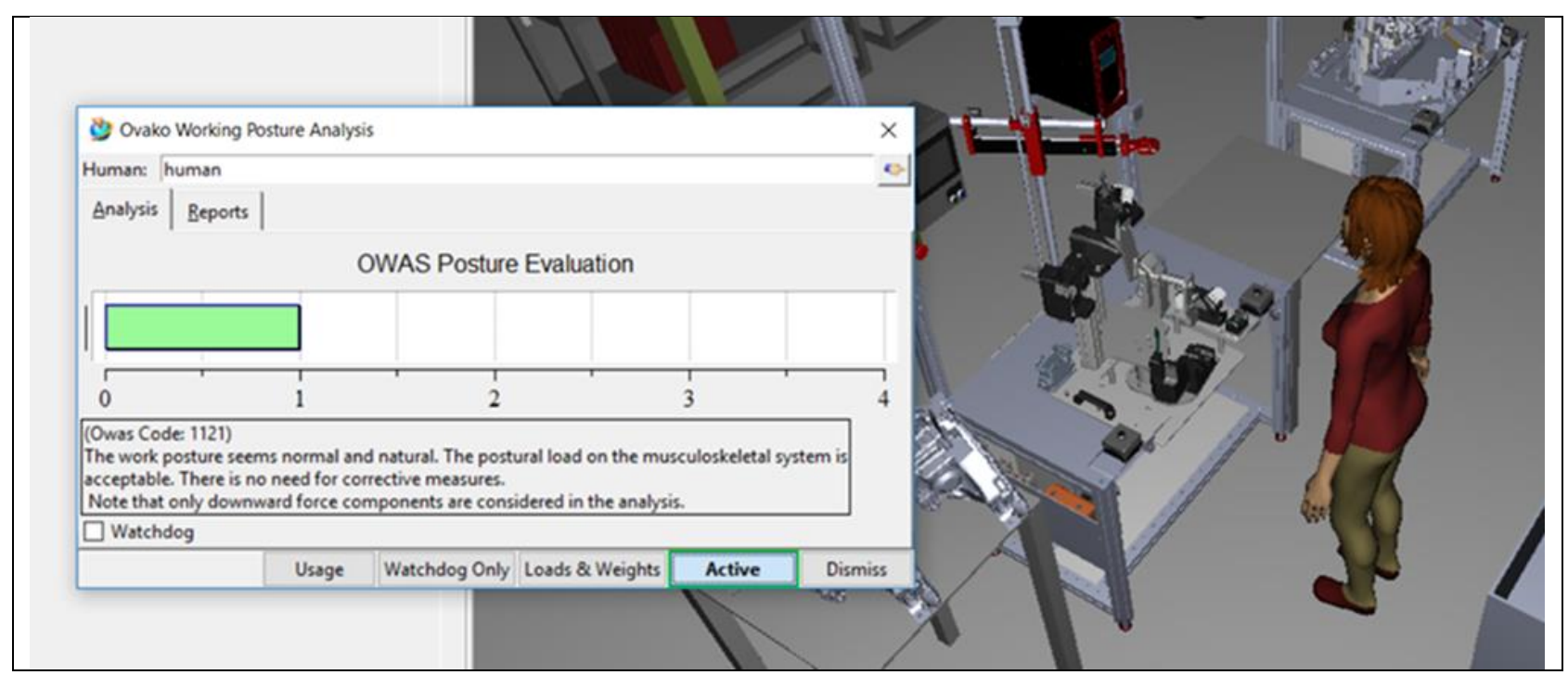

Fig. 4. Computer aided OWAS analysis

For the selected OWAS analysis the program package Jack assess workers movements with four levels:

- Green; the work posture is normal and natural. The postural load on the musculoskeletal system is acceptable and there is no need for corrective measures

- Yellow; the work posture may have harmful effects on the musculoskeletal system. Corrective measures are encouraged.

- Orange; this work posture will cause harmful levels of stress on the musculoskeletal system. Corrective measures must be taken as soon as possible

- Red; Posture has a very harmful effect; corrective measures must be taken immediately

As mentioned before the biggest problem with well-known ergonomics methods is that they do not include assessment measures for workers with disabilities. The same situation is with the software packages that use digital human models for workers movement simulation and analysis. This presents a great defectiveness that should be addressed in the future. For the purpose of our research we decided that only first level assessments will be considered as acceptable for workers with disabilities. All other levels were considered as potentially harmful for workers with disabilities (Fig. 5). On Fig. 6 workers movements in the indicator light assembly workplace are presented. 
Vujica Herzog, N.; Buchmeister, B. \& Harih, G.: Ergonomic Workplace Design for...
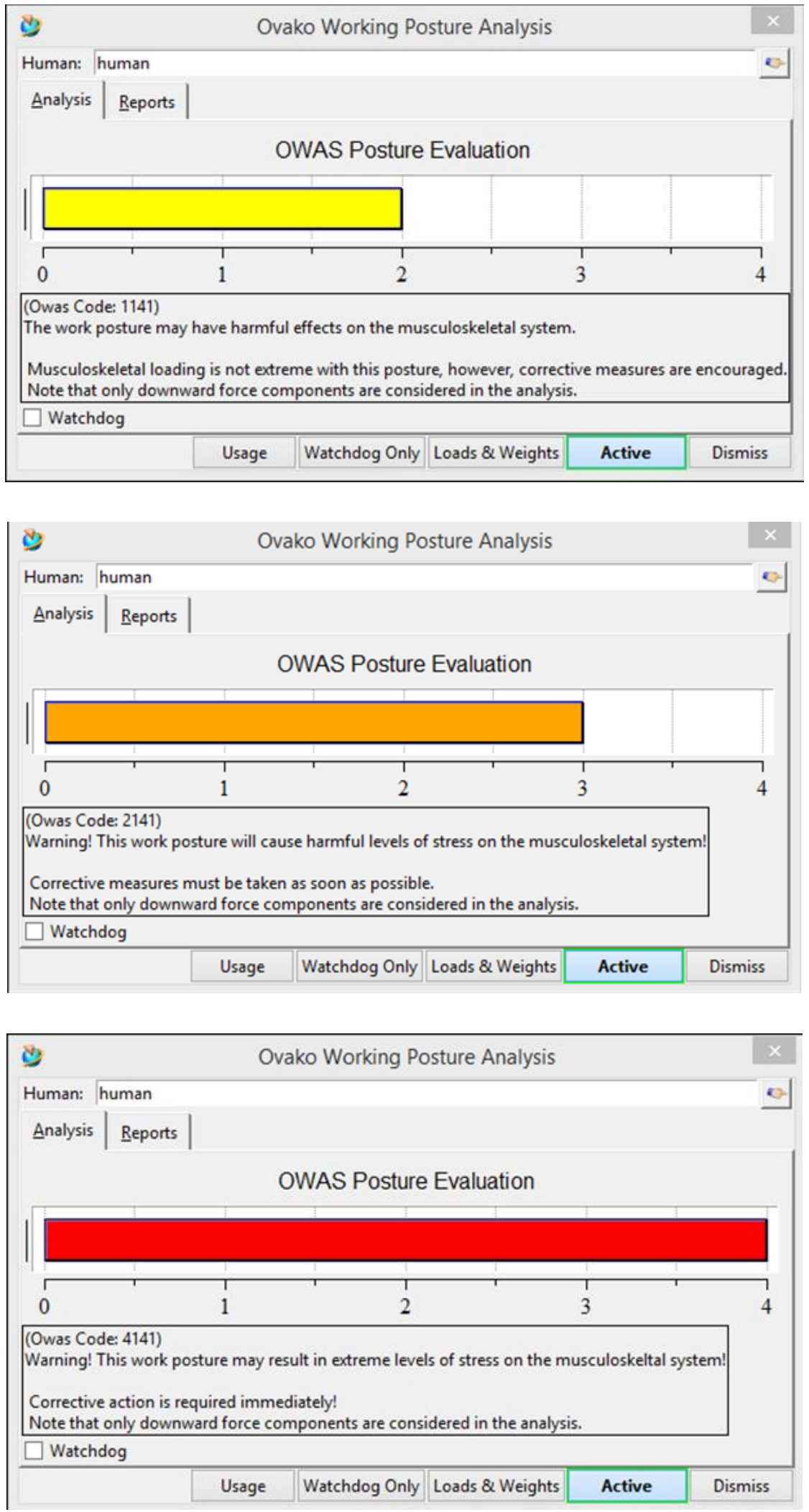

Fig. 5. OWAS analysis - harmful levels for workers with disabilities 

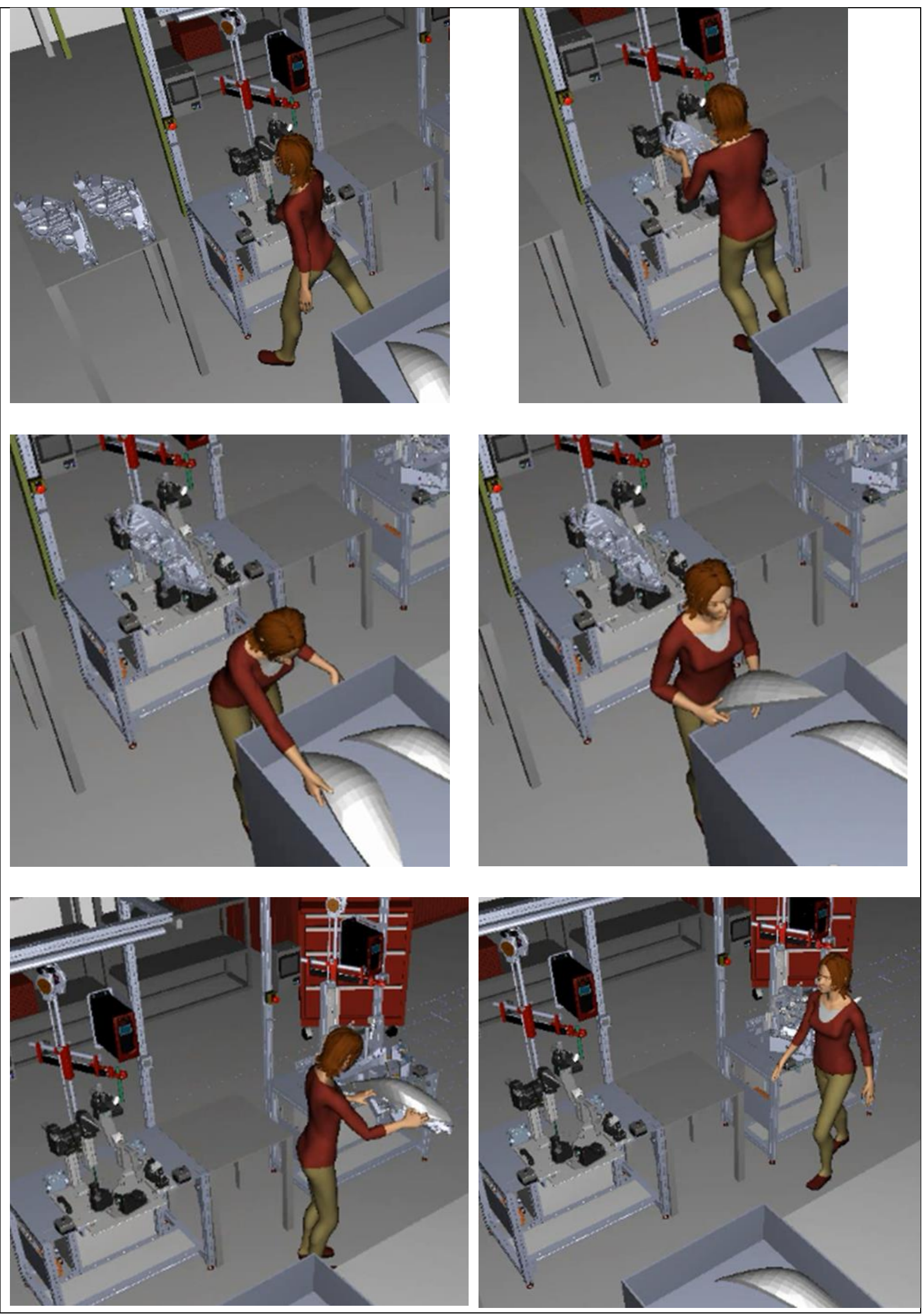

Fig. 6. Workers movements in the indicator light assembly workplace 
Vujica Herzog, N.; Buchmeister, B. \& Harih, G.: Ergonomic Workplace Design for...

For body posture on Fig. 7 we got results from OWAS analysis signed with yellow which means that changes are needed in the near future and the message is written: 'The work posture may have harmful effects on the musculoskeletal system.' This position could be conditionally accepted for healthy worker but not for worker with disabilities that was selected for this workplace. Suggested measure could be changing the position of crates to achieve easier reach and taking component parts from crates.

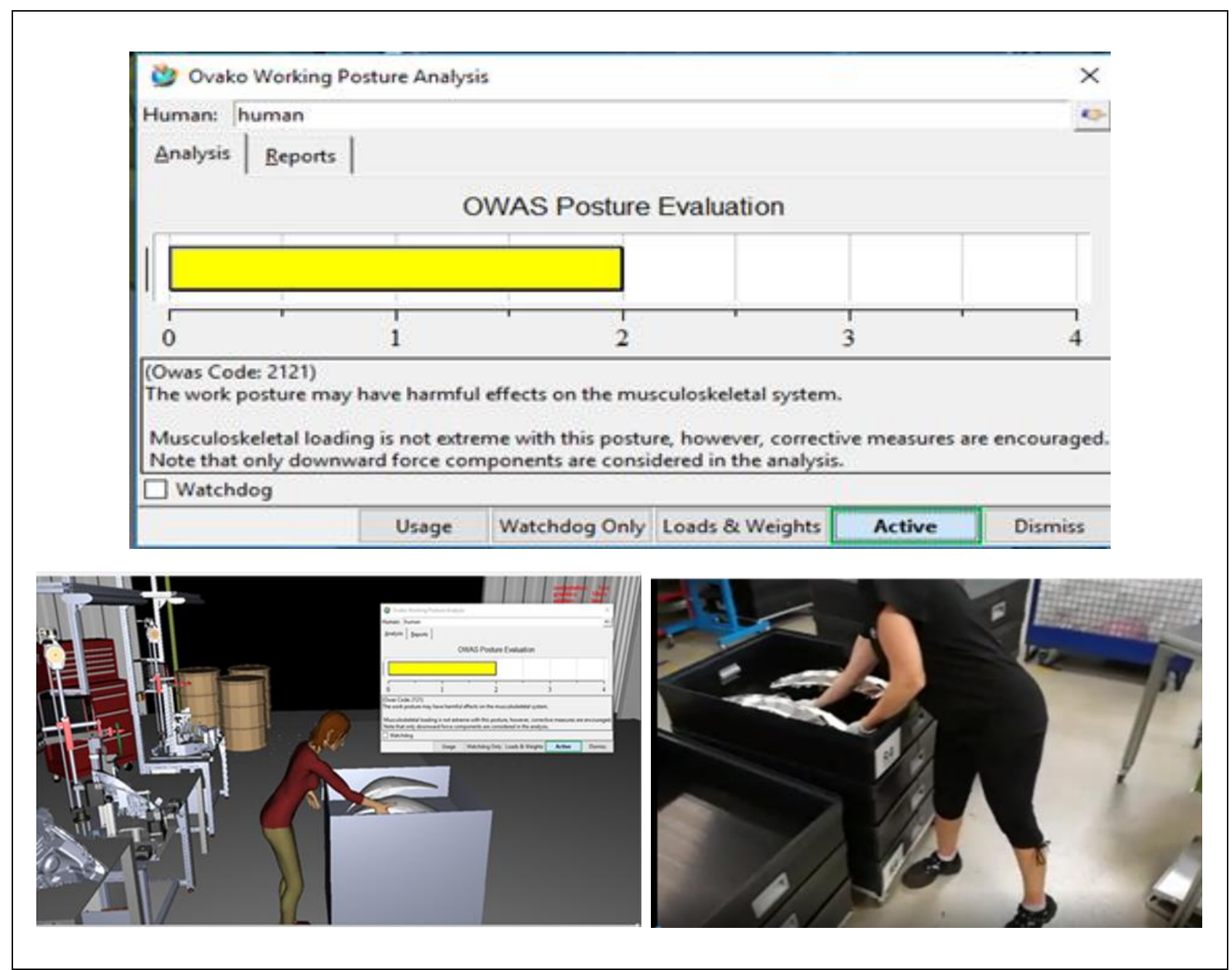

Fig. 7. Worker posture during taking parts - changes are needed in the near future

Another potentially harmful movement is presented on Fig. 8. Suggested measure for this posture could be changing the tool to enable easier screwing and taking component parts from the toll.

Based on all performed analyses a preposition was made for new ergonomically designed workplace (Fig. 9). In the case of the indicator light assembly workplace, the existing workplace required a standing posture to be able to reach for the reflector and other assembly parts located in standardised containers.

It has been identified that the current workplace would result in critical postures, which would affect workers with disabilities in regard to the lumbar spine, neck spine and shoulder and hand joint areas. 


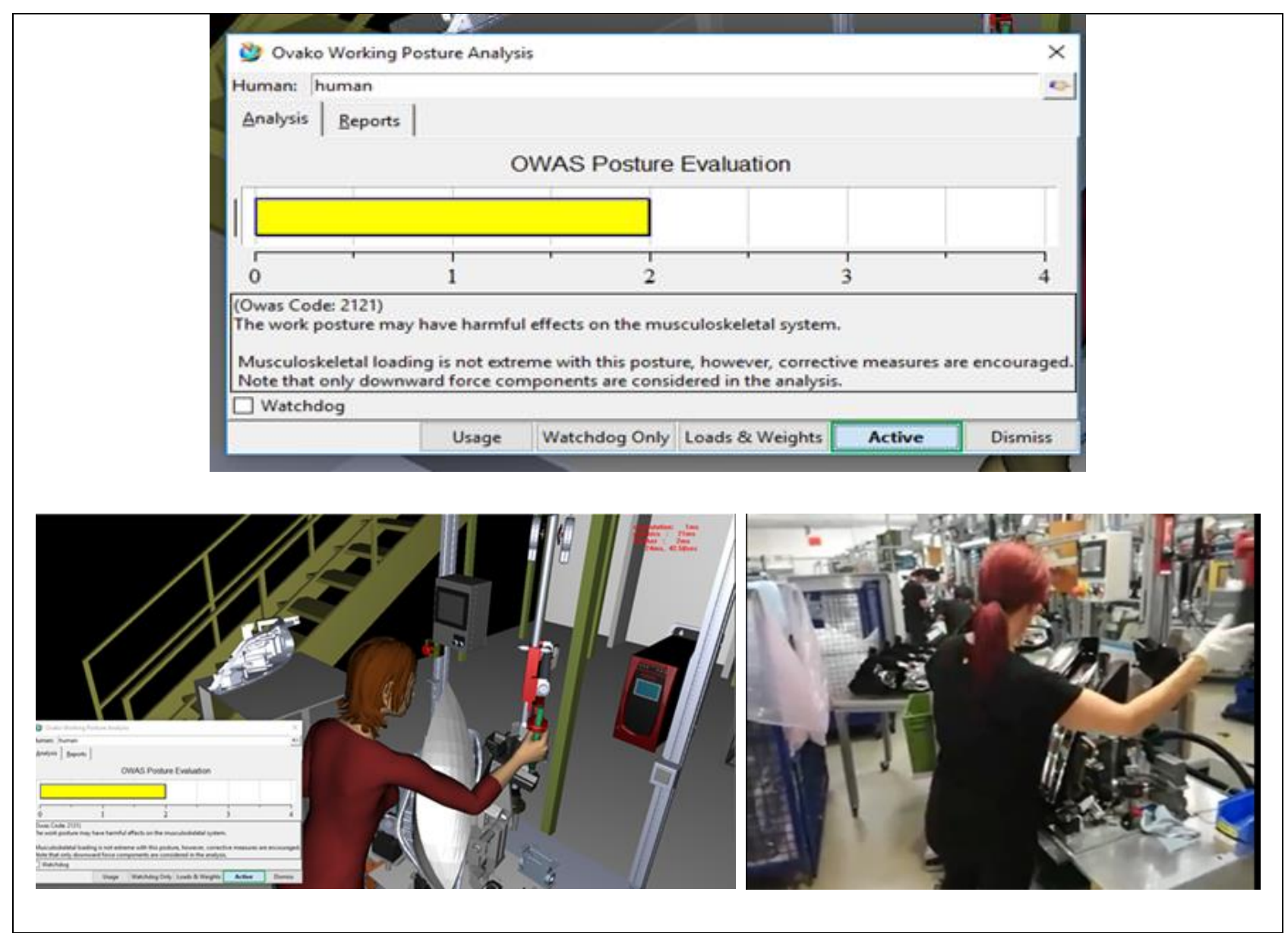

Fig. 8. Worker posture during screwing - changes are needed in the near future

The system suggested the following adjustments: Provide leg room, adjust workplace height for sitting posture, placement for reach. Based on this recommendation, the workplace working desk is now adjustable in height and can be lowered from $90 \mathrm{~cm}$ to $75 \mathrm{~cm}$, which makes standing and sitting work possible. For reach, containers have been put closer to the working area and lowered, to reduce the need to lean when reaching for the parts. Additionally, the front containers have been tilted for reachability and lowering the risk of shoulder and hand joint strain and injury (Fig. 9).

\section{Conclusions}

Workers with disabilities present a large population of workforce and represent a great part of working-age persons that are unable to work. Most barriers to employment included discrimination by employers, lack of suitable workplace accommodations, inadequate job training and others. Since work is one of the basic factors of human life, appropriate designed workplace can contribute to healthy and satisfied worker and this fact is even more important when we talk about workers with disabilities. It is also generally known that stress at work and possible injuries are usually connected with non-adequate workplace design. In the field of ergonomics workplace design there is rarely any expert knowledge regarding workers with disabilities. 


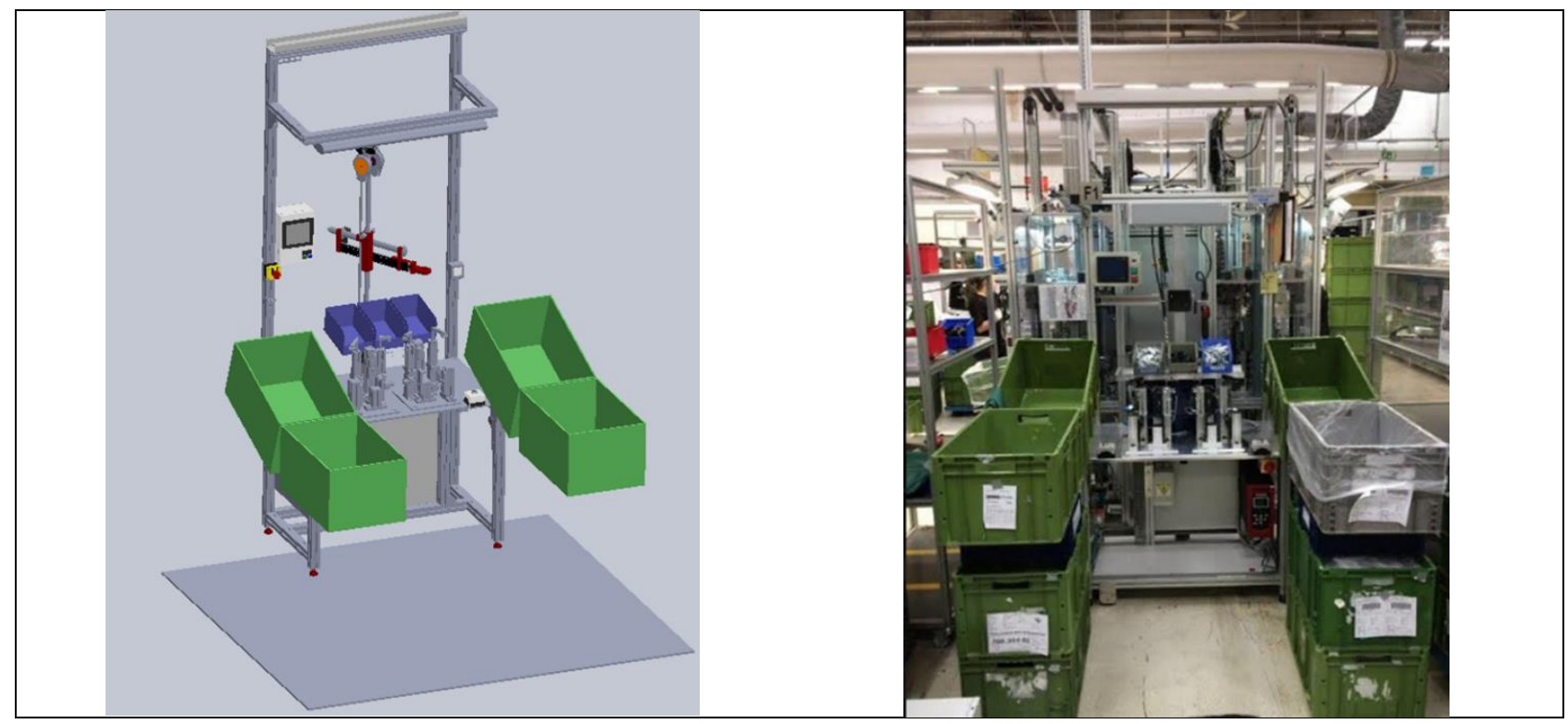

Fig. 9. Workplace after the adjustments suggested by the system - left, virtual

On the other hand, employers are faced with the problem of identifying suitable workplaces for workers with disabilities, and supplying the needed requirements to integrate them with other healthy workers in working environment. By ergonomic workplace design it is possible to adapt work to a human's physical and mental characteristics and to reduce or prevent additional adverse effects on health.

With presented approach of ergonomically designed workplace for workers with disabilities we can assure them suitable and appropriate working environment. New designed workplace will be in future tested for suitability for at least three month and the selected worker will cooperate with his outputs through conversations and questionnaires to examine his satisfaction with integrated employment approach.

\section{Acknowledgements}

The authors acknowledge that the Grant P2-0190 were supported financially by the Slovenian Research Agency. The research was also funded by The Public Scholarship, Development, Disability and Maintenance Fund of the Republic of Slovenia.

\section{References}

Abrahamsson, L. (2000). Production economics analysis of investment initiated to improve working environment. Applied Ergonomics, Vol. 31, pp. 1-7.

Andrejiova, M.; Kralikova, R.; Wessely, E.; Sokolova, H. (2012). Assesment of the Microclimate in the Work Environment, Chapter 42 in DAAAM International Scientific Book 2012, pp. 509-516, B. Katalinic (Ed.), Published by DAAAM International, ISBN 978-3-901509-86-5, ISSN 1726-9687, Vienna, Austria, Doi: 10.2507/daaam.scibook.2012.42.

Contreras DG, et al., (2006). Socio-economic impact of disability in Latin America: Chile and Uruguay. Santiago, Universidad de Chile, Departemento de Economia. 
Jones, M. K., Latreille, P. L., \& Sloane, P. J. (2006). Disability, gender, and the British labour market. Oxford Economic Papers, Vol. 58, Nr. 3, pp. 407-449.

Fomin, S. (2015). Aspects of application of virtual environments at training of specialists in the field of ICT, Chapter 17 in DAAAM International Scientific Book 2015, pp. 189-198, B. Katalinic (Ed.), Published by DAAAM International, ISBN 9783-902734-05-1, ISSN 1726-9687, Vienna, Austria, Doi: 10.2507/daaam.scibook.2015.17.

Fritzsche, L., Wegge, J., Schmauder, M. (2014). Good ergonomics and team diversity reduce absenteeism and errors in car manufacturing, Ergonomics, Vol. 57, Nr. 2, pp. 148-161.

Houtenville AJ, et al., (2009). Counting working-age people with disabilities. What current data tell us and options for improvement. Kalamazoo, W.E. Upjohn Institute for Employment Research.

Yang, W., Dall, T., Beronija, K., Lin, L., Semilla, A.P., Chakrabati, R., Hogan, P.F., (2018), Economic Costs of Diabetes in the US in 2017, Diabetes care, Vol. 41, Nr. 5, pp. 917-928.

Genowska, A., Fryc, J., Pinkas, J., Jamiolkowski, J., Szafraniec, K., Szpak, A., Bojar, I., (2017). Social costs of loss in productivity-related absenteeism in Poland, International Journal of Occupational Medicine and Environmental Health, Vol. 30, Nr. 6, pp. 917-932.

Jones, M. K. (2016). Disability and perceptions of work and management. British Journal of Industrial Relations, Vol. 54, Nr. 1, pp. 83-113.

Karhu, U.; Kansi, P.; Kuorinka, I. (1977). Correcting working postures in industry: a practical method for analysis. Applied Ergonomics, Vol. 8, No. 4, pp. 199-201, ISSN: 0003-6870.

Karhu, O.; Harkoen, R.; Sorvali, P.; Vespalainen, P. (1981). Observing working postures in industry: examples of OWAS application. Applied Ergonomics, Vol. 12, No. 1, pp. 13-17, ISSN: 0003-6870.

Kregel, J., \& Dean, D. H. (2002). Sheltered vs. Supported Employment: A Direct Comparison of Long-Term Earnings Outcomes for Individuals with Cognitive Disabilities." In Achievements and Challenges in Employment Services for People with Disabilities: The Longitudinal Impact of Workplace S.

Kruse, D., \& Schur, L. (2003). Employment of people with disabilities following the ADA. Industrial Relations: A Journal of Economy and Society, Vol. 42, No.1, pp. 3166.

Lengnick-Hall, M. L., Gaunt, P. M., \& Kulkarni, M. (2008). Overlooked and underutilized: People with disabilities are an untapped human resource. Human Resource Management: Published in Cooperation with the School of Business Administration, The University of Michigan and in alliance with the Society of Human Resources Management, Vol. 47, No. 2, pp. 255-273.

Martinez, K. (2013). Integrated employment, Employment First, and US federal policy. Journal of Vocational Rehabilitation, Vol.38, No. 3, pp. 165-168.

Mitra S. (2008). The recent decline in the employment of persons with disabilities in South Africa, 1998-2006. South African Journal of Economics, Vol. 76, pp. 480-492. doi:10.1111/j.1813-6982.2008.00196.x 
Vujica Herzog, N.; Buchmeister, B. \& Harih, G.: Ergonomic Workplace Design for...

Mitra S, Sambamoorthi U. (2006). Employment of persons with disabilities: evidence from the National Sample Survey. Economic and Political Weekly, Vol. 41, p.199-203. Murphy, S. T., \& Rogan, P. M. (1995). Closing the shop: Conversion from sheltered to integrated work: ERIC.

Parent-Johnson, W., \& Owens, L. (2017). Supported and customized employment Handbook of Positive Psychology in Intellectual and Developmental Disabilities (pp. 329-338): Springer.

Riesen, T., Morgan, R. L., \& Griffin, C. (2015). Customized employment: A review of the literature. Journal of Vocational Rehabilitation, Vol. 43, No. 3, pp. 183-193.

Parent-Johnson, W., \& Owens, L. (2017). Supported and customized employment Handbook of Positive Psychology in Intellectual and Developmental Disabilities (pp. 329-338): Springer.

Schur, L., Colella, A., Adya, M. (2016). Introduction to special issue on people with disabilities in the workplace, The International Journal of Human Resource Management, Vol. 27, No. 14, 1471-1476.

Spyropoulus, E.; Chroni, E.; Katsakiori, P. \& Athanassiou, G. (2013). A quantitative approach to assess upper limb fatigue in the work field. Occupational Ergonomics, Vol. 11, pp. 45-57.

Vujica Herzog, N. \& Buchmeister, B. (2014). Ergonomic workplace design in the clothing shop, Chapter xx in DAAAM International Scientific Book 2014, pp. 109120, B. Katalinic (Ed.), Published by DAAAM International, ISBN 978-3-901509988, ISSN 1726-9687, Vienna, Austria DOI: 10.2507/daaam.scibook.2014.xx

Vujica Herzog, N. \& Buchmeister, B. (2015). The review of ergonomics analysis for body postures assessment, Chapter xx in DAAAM International Scientific Book 2015, pp. 153-164, B. Katalinic (Ed.), Published by DAAAM International, ISBN 978-390150998-8, ISSN 1726-9687, Vienna, Austria DOI: 10.2507/daaam.scibook.2015.14 World report on disability 2011 (2011). World Health Organization.

Yelln, E. H., \& Trupin, L. (2003). Disability and the characteristics of employment. Monthly Lab. Rev., 126, pp 20. 